\title{
On the use of buffy or whole blood for obtaining DNA or RNA of high quality and functionality: What is the best option?
}

Ferro P. ${ }^{1}$, Díaz T. ${ }^{1}$, Ortega-Pinazo J. ${ }^{2}$, Gómez J.M. ${ }^{3}$, Martínez B. ${ }^{1}$, Fernández M.I. ${ }^{1}$, Martín I. ${ }^{1}$, Jiménez A. ${ }^{1}$, Acosta-Andrade C. ${ }^{1}$ and Hortas M.L. ${ }^{4}$

${ }^{1}$ Andalusian Public Health System Biobank, Instituto de Investigación Biomédica de Málaga (IBIMA), Sanitary Distric of Málaga, University of Málaga.

${ }^{2}$ Neurology Service, Instituto de Investigación Biomédica de Málaga (IBIMA), Sanitary Distric of Málaga, University of Málaga.

${ }^{3}$ Genetic Platform, Instituto de Investigación Biomédica de Málaga (IBIMA), Sanitary Distric of Málaga, University of Málaga.

${ }^{4}$ Costa del Sol Sanitary Agency, Sanitary District of Málaga.

\section{INTRODUCTION}

Human Biobanks are biorepositories of collection of biological samples and health information which allow the organization of biomedical research for upgrading the knowledge of human disorders from different diseases (cancer, allergy, rare diseases, etc) and reach real answers for diagnosis and treatment. A wide range of samples can be stored in these biorepositories as hair, nails, urine, tissue, whole blood (WB), red blood cells (RBC), buffy coat (BC), plasma, serum, DNA, RNA, etc. Among these $B C$ and WB are very appreciated by researchers because they can obtain DNA and RNA from this type of samples. Some preliminary studies have been performed in animals to evaluate the quality and functionality of the nucleic acids obtained from these matrices $(B C \text { and } W B)^{1,2}$, notwithstanding deeper studies would be interesting in order to establish the best matrix for this purpose and to be able to optimize the biobanks storage conditions.

AIM

The aim of this study is to evaluate the functionality and quality of the DNA and RNA obtained from whole blood and buffy coat to determine the best storage conditions and the optimal extraction matrix.

\section{METHODS AND MATERIAL}

Whole blood was extracted from ten healthy volunteers by venipuncture blood in the arm. For each volunteer 2 EDTA tubes, 2 citrate tubes and 1 Paxgene tube were obtained. The samples were collected and managed by the Biobank of the Public Health System of Andalusia (BSSPA) following standard work protocols. Patients participating in the study provided the informed consent of Biobanco.

After extraction some samples were processed immediately and others were pre-processed and storied at $-80 \stackrel{\circ}{\circ}$ until use. DNA and RNA were extracted following the manufacturer's suppliers and quality and integrity were analysed by spectrophotometry and agarose gel. The functionality was evaluated by PCR using the primers Forward 5'-GCCTTCCCAACCATTCCCTTA- 3' and reverse 5'-TCACGGATTTCTGTTGTGTTTC- 3' which amplify a fragment of 429 base pairs of the HGH gene.

RESULTS

DNA extraction showed similar concentrations for BC and whole cells in samples extracted the day 0 , but in samples stored 30 days buffy coat showed a reduction in the efficiency of $82 \%$ less when was compared with buffy coat extracted at day 0 , while whole blood showed only a reduction of $55 \%$ (Table 1 and Figure 1). However, the integrity of the all samples and the functionality was not altered with the storied time (Figure 2).

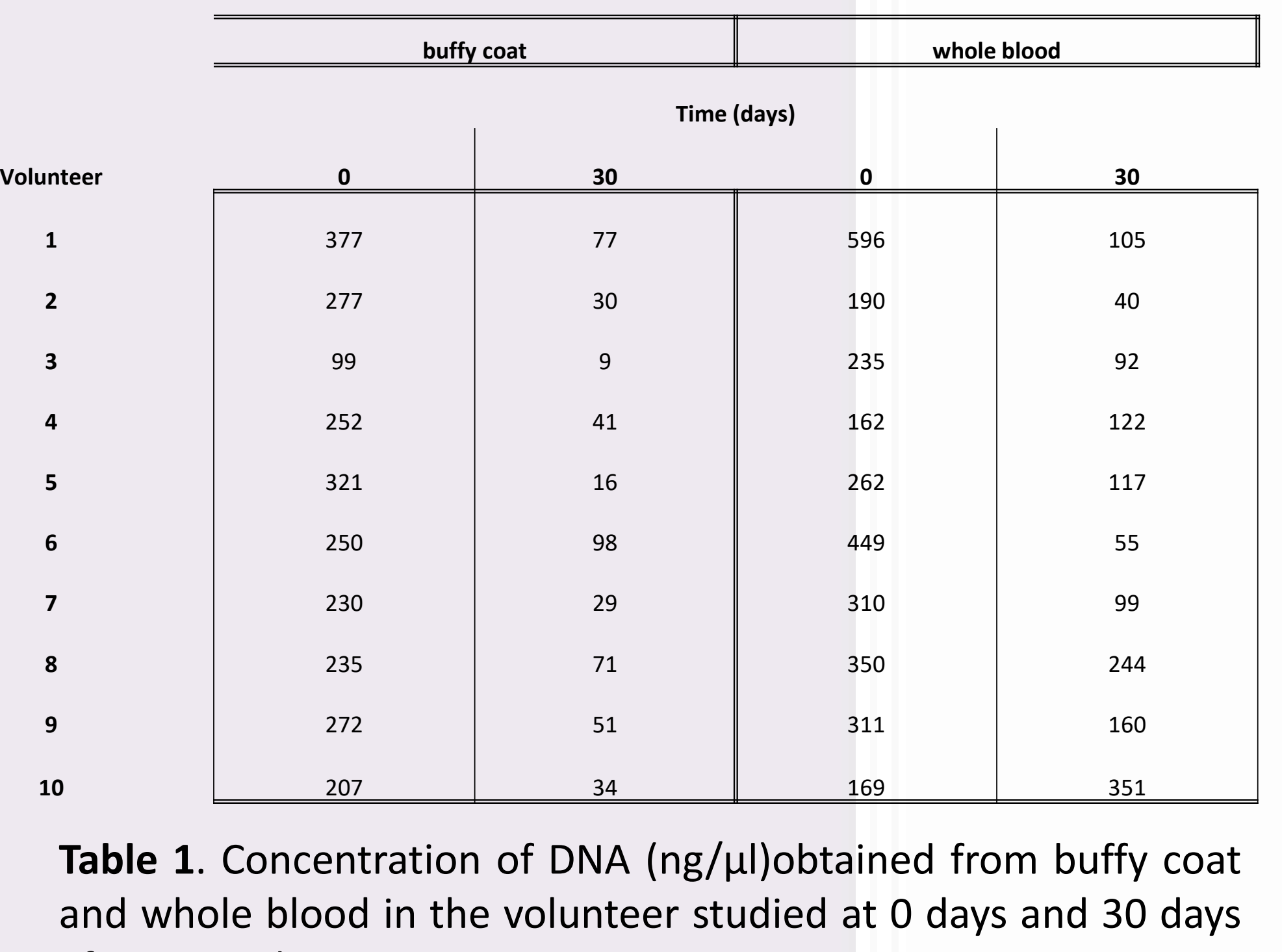
after storied at $-80^{\circ} \mathrm{C}$.

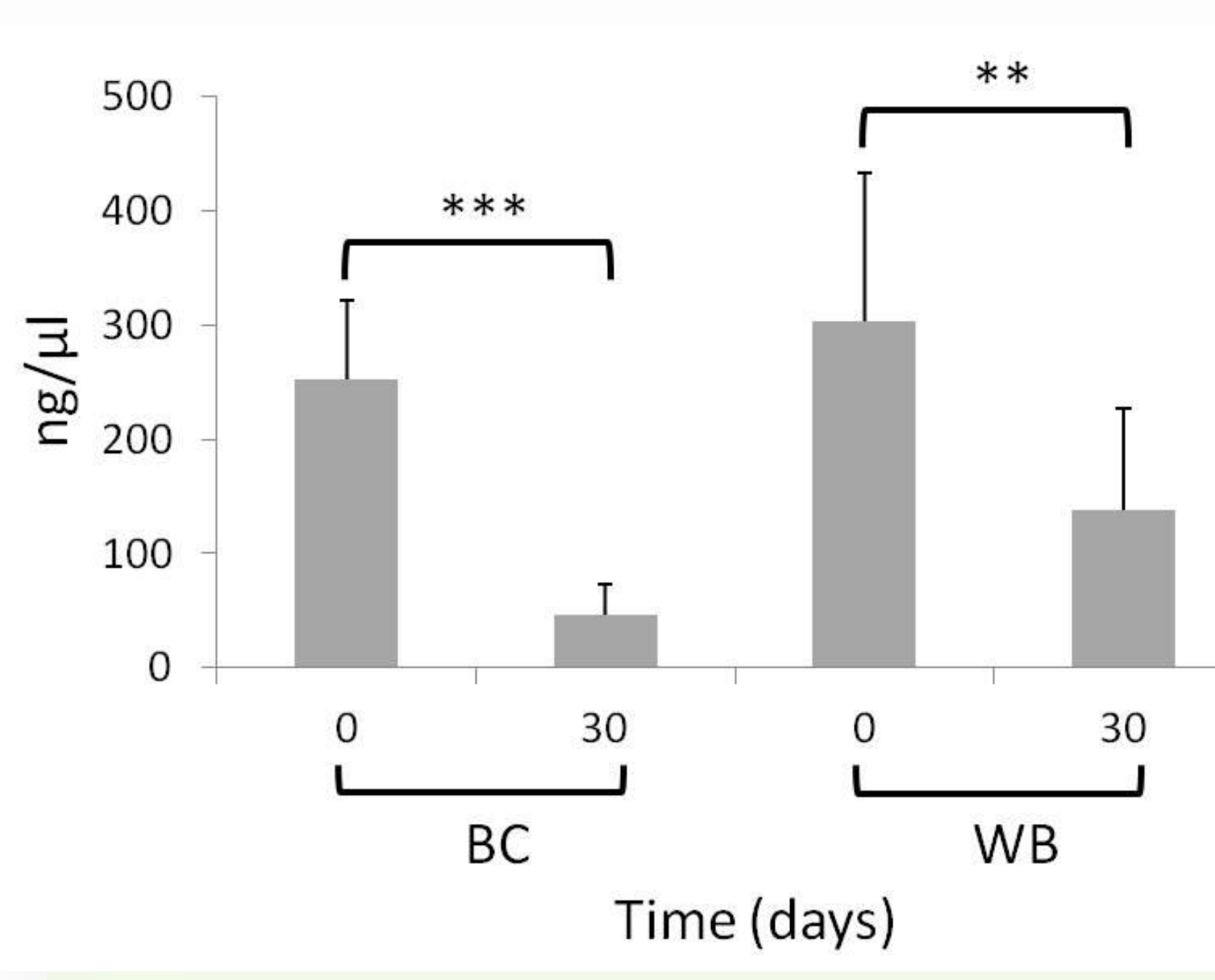

Figure 1. Comparison between the concentration obtained from buffy coat (BC) and whole blood (WB) at 0 days and storied at $-80^{\circ} \mathrm{C}$ for 30 days. Mean values of 10 volunteer for each condition are represented. Bars show standar deviations. Levels of statistical significance compared with
storied time: $* 0.01<p \leq 0.05, * * 0.001<p \leq 0.01$, and $* * * *$ $\leq 0.001$ (t'student test)

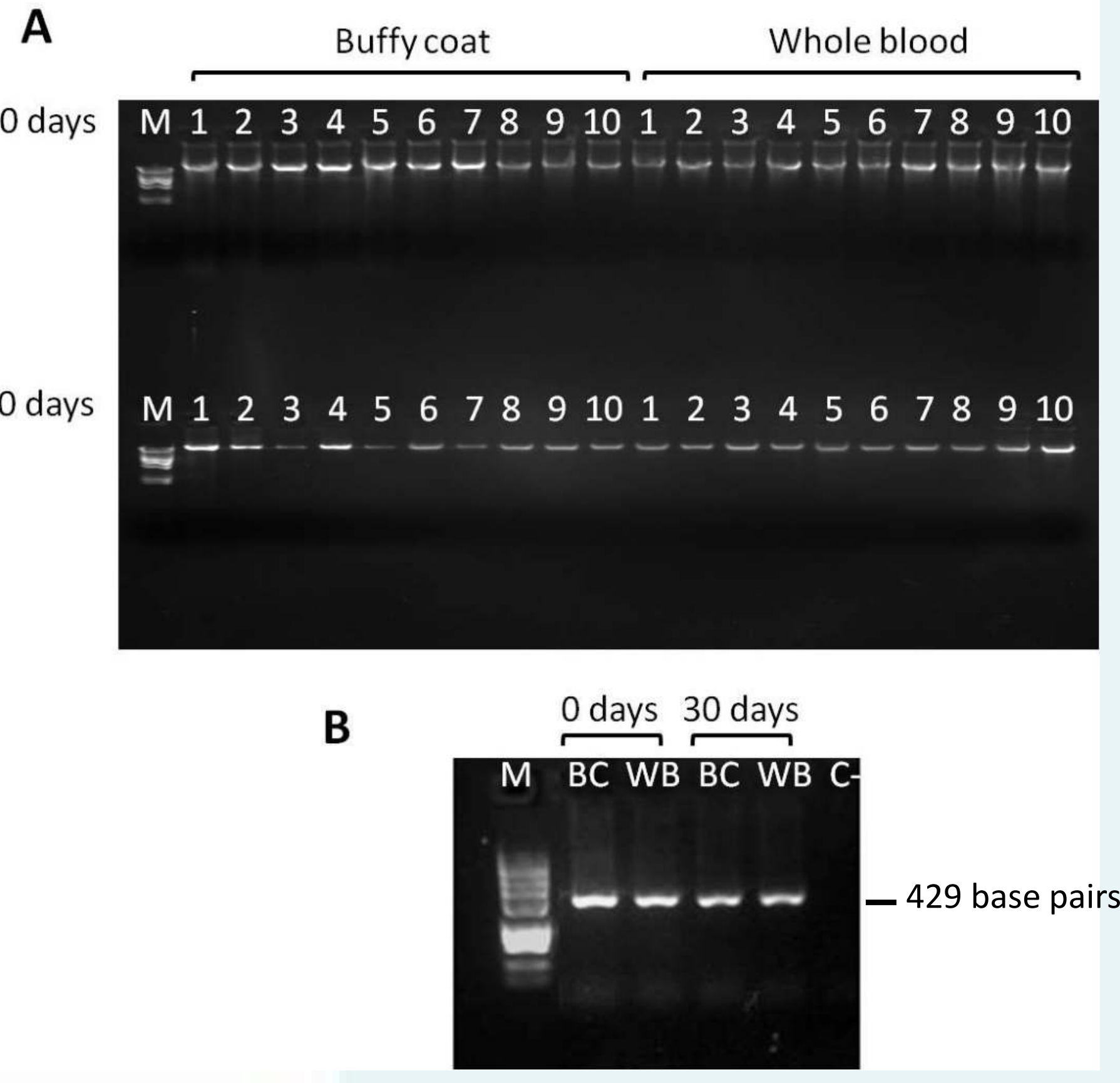

Figure 2. Integrity and funcionality of the DNA extracted from buffy coat (BC) and whole blood (WB) at 0 days and 30 days after extraction. A. Genomic DNA extracted from each volunteer in agarose gel of $1 \%$ (number 1 to 10 reference to volunteer. M- Molecular weight marker). B. PCR of the gene vol from genomi

On the other hand, RNA was obtained from cells purified from EDTA tubes and frozen at -1960C for 30 days. RNA from cells storied for 30 days showed a loss of efficiency of $48 \%$ when was compared with RNA extracted from cells purified at day 0 (Figure 2).

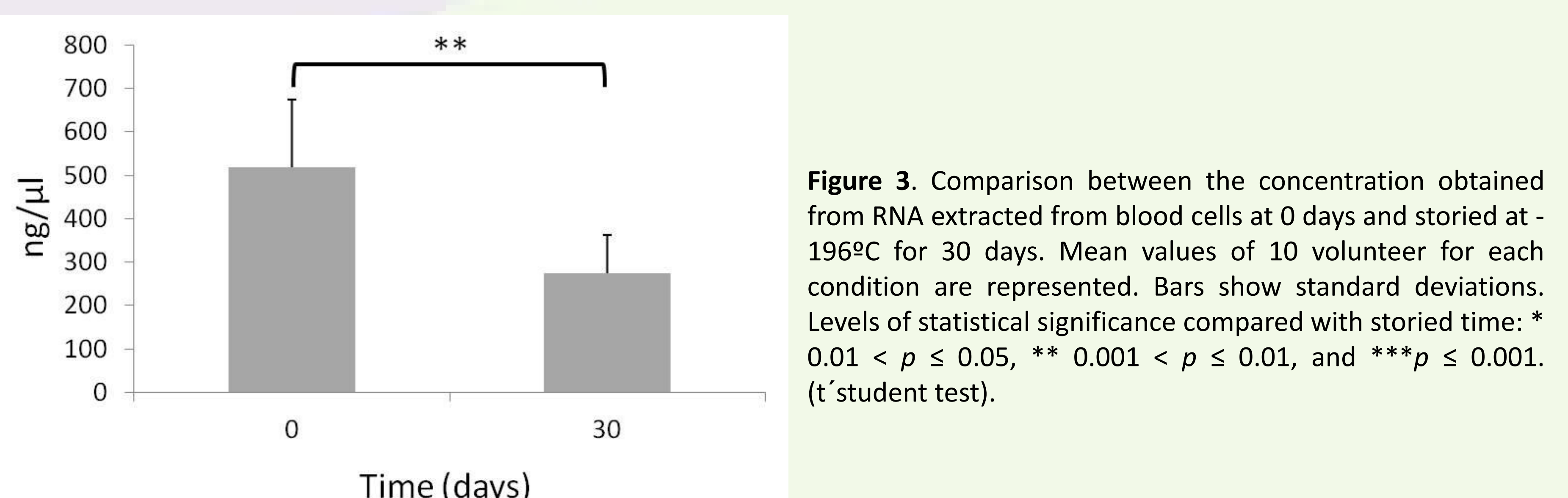

CONCLUSION

In samples stored at $-800^{\circ} \mathrm{C}$ is better the use of whole blood because the mount of DNA obtained is higher when is compared with buffy coat. In samples extrated in fresh buffy coat is better because reduce the cost of the extraction and the time of the protocol.

In general, The storied affect the quantity of the nucleic acid extracted, so it is not recommended the storied of the samples for a long time.

\section{ACKNOELEDGMENTS}

This work was carried out with the financial support of the Biobank Platform PT13/0010/0006, Health Institute Carlos III (ISCIII,Madrid, Spain)

BIBLIOGRAPHY

1. Psifidi A, Dovas Cl, Bramis G, Lazou T, Russel CL, Arsenos G, Banos G. Comparison of eleven methods for genomic DNA extraction suitable for large-scale wholegenome genotyping and long-term DNA banking using blood samples. Plos One. 2015;10(1):e0115960

2. Gail MH, Sheehy T, Consentino M, Pee D, Diaz-Mayoral Na, Garcia-Closas M, Caporaso NE, Pitt K, Ziegler RG. Maximizing DNA yield for epidemiologic studies: no more buffy coats? Am J Epidemiol. 2013;178(7):1170-6. 